\title{
Facile, Green Synthesis of Large Single Crystal Copper Micro and Nanoparticles with Ascorbic Acid and Gum Arabic
}

\author{
Preston B. Landon ${ }^{* 11,2}$, Alexander H. Mo ${ }^{\# 3}$, Carlos T. Ramos ${ }^{4}$, Jose J. Gutierrez ${ }^{4}$, Ratnesh Lal ${ }^{* 1,2,3}$ \\ ${ }^{1}$ Department of Mechanical Engineering, University of California, San Diego, USA \\ ${ }^{2}$ Department of Bioengineering, University of California, San Diego, USA \\ ${ }^{3}$ Materials Science and Engineering Program, University of California, San Diego, USA \\ ${ }^{4}$ Department of Chemistry, The University of Texas Pan American, Edinburg, USA \\ Email: "plandon@ucsd.edu; rlal@ucsd.edu
}

Received June 29, 2013; revised August 5, 2012; accepted August 12, 2013

Copyright (C) 2013 Preston B. Landon et al. This is an open access article distributed under the Creative Commons Attribution License, which permits unrestricted use, distribution, and reproduction in any medium, provided the original work is properly cited.

\begin{abstract}
Large single crystal colloidal copper particles with diameters between $0.5-2 \mu \mathrm{m}$ were created using a green synthesis process. The process used ascorbic acid to reduce Schweizer's reagent created in situ using copper salts in the presence of various concentrations of gum arabic. The Schweizer's reagents were created by varying the concentrations of ammonium hydroxide and copper nitrate solutions, copper hydroxide, or copper sulfate. The $\mathrm{pH}$ of the solution was controlled by the addition of ascorbic acid. Particle formation was favored at high temperature using copper sulfate at $\mathrm{pH}$ values ranging from 7.5 to 9 , while the optimal formation occurred at a $\mathrm{pH}$ value of 8.5. At high concentrations, copper particle formation was found to occur from the aggregation of smaller particles which continued to nucleate once aggregated, and this resulted in the creation of globular particles and large aggregates of micron-sized particles. The addition of gum arabic resulted in the creation of large single crystal particles that did not aggregate. SEM was used to observe the effect of increasing gum arabic concentrations and EDX was used to confirm the elemental purity of the particles.
\end{abstract}

Keywords: Copper; Green Synthesis; Microparticles; Nanoparticles; Gum Arabic; Ascorbic Acid

\section{Introduction}

Colloidal copper particles are of great research interest because of their low cost, high conductivity, unique chemical [1], thermal [2], and optical [3] properties. A variety of physical [4,5] and chemical [6-12] methods exist for the synthesis of colloidal copper. The parameters under study are typically the nature of the copper salts $[10,11]$, reducing agents[11,12], binding agents $[9$, 12], temperature [7], $\mathrm{pH} \mathrm{[6],} \mathrm{and} \mathrm{catalyst} \mathrm{[8].} \mathrm{In} \mathrm{a} \mathrm{cost-}$ effective and environmentally friendly process, however, the conditions must allow a high efficiency for the formation of particles with minimal risks to people and environment and the reagents must be readily available and inexpensive. Recently, a novel green aqueous method for the formation of colloidal copper has been reported $[13,14]$. Here, we report a process to synthesize colloidal

\footnotetext{
"Corresponding author.

"These authors contributed equally to this work.
}

copper using copper sulfate and ascorbic acid. We also report the effect of $\mathrm{pH}$ and introduce a way to create large single colloidal copper particles using gum arabic.

Using the readily available copper sulfate and ammonium hydroxide dissolved in deionized (DI) water, solutions of Schweizer's reagent $\left[\mathrm{Cu}\left(\mathrm{NH}_{3}\right)_{4}\left(\mathrm{H}_{2} \mathrm{O}\right)_{2}\right](\mathrm{OH})_{2}$ were prepared and optimized for use with ascorbic acid (vitamin C). Schweizer's reagent is formed by the chemical reaction:

$$
\begin{gathered}
\mathrm{CuSO}_{4}(a q)+2 \mathrm{OH}^{-}(a q) \rightarrow \mathrm{Cu}(\mathrm{OH})_{2}(a q)+\mathrm{SO}_{4}^{2-}(a q) \\
\mathrm{Cu}(\mathrm{OH})_{2}(a q)+4 \mathrm{NH}_{4} \mathrm{OH}(a q) \\
\rightarrow\left[\mathrm{Cu}\left(\mathrm{NH}_{3}\right)_{4}\left(\mathrm{H}_{2} \mathrm{O}\right)_{2}\right](\mathrm{OH})_{2}(a q)+2 \mathrm{H}_{2} \mathrm{O}
\end{gathered}
$$

The inspiration for this particular method came from observing the reduction of Tollen's reagent with different agents including ascorbic acid.

Tollen's reagent is a silver-ammonia metal-ion com- 
plex that deposits a shiny, metallic silver film onto its container upon reduction and has been used for making mirrors for hundreds of years. Noting the similarities between the Tollen's and Schweizer's reagent, initial testing of different reducing agents found that only ascorbic acid was effective in producing a copper film $[13,14]$.

To improve the quality of the formed crystals, a binding and capping agent, gum arabic, was used. Gum arabic is derived from hardened sap of the acacia tree and has previously been demonstrated to form well-developed gold and silver particles $[15,16]$ and nanoparticle functionalization [17]. To the best of the authors' knowledge, this is the first reported usage of gum arabic in the formation of copper micro and nanoparticles.

Schweizer's reagent/ascorbic acid reaction solutions have been optimized adjusting levels of copper sulfate, ammonium hydroxide, and ascorbic acid and observing the copper film quality on the reaction vials. Once optimized, solutions were prepared with increasing amounts of gum arabic, while heated and stirred. The supernatant of each sample was extracted, centrifuged, and dried on a SEM post. SEM images were then used to observe gum arabic's effects on copper formation.

\section{Materials and Methods}

\subsection{Preparation of Solutions}

Stock solutions of copper sulfate consisted of $12.5 \mathrm{~g}$ of $\mathrm{CuSO}_{4} \cdot 5 \mathrm{H}_{2} \mathrm{O}$ (Sigma, St Louis, MO), a certain amount of concentrated $\mathrm{NH}_{4} \mathrm{OH}$ (Fischer Scientific, Pittsburgh, PA), dissolved in DI water (MilliQ, Millipore, Billerica, MA) with a resistance of $18.6 \mathrm{M} \Omega$ to a total volume of 500 $\mathrm{mL}$. A $0.3 \mathrm{M}$ reducing solution of L-ascorbic acid was prepared with $52.8 \mathrm{~g}$ of L-ascorbic acid (Sigma, St. Louis, MO) in $500 \mathrm{~mL}$ of DI water. Different reaction conditions were tested in $20 \mathrm{~mL}$ glass vials by adding a certain volume of copper sulfate solution to a certain volume of L-ascorbic acid solution for a total of $20 \mathrm{~mL}$. Solution $\mathrm{pH}$ was monitored initially and after conclusion of the reaction with a $\mathrm{pH}$ monitor (Accumet Excel XL60, Fischer Scientific). Varying amounts of gum arabic were introduced into the optimized reaction mixture in order to observe its effects on copper crystal formation.

\subsection{Preparation for Imaging}

After 72 hours to ensure reaction completion, particle suspensions were transferred in entirety to a $50 \mathrm{~mL}$ conical centrifuge tubes (Corning Inc., Corning, NY) and cen- trifuged at room temperature at $3220 \mathrm{~g}$ for $40 \mathrm{~min}-$ utes. Afterwards the supernatant was disposed. The particles were washed twice by resuspension of the pellet in $50 \mathrm{~mL}$ of DI water, centrifuging, disposing the supernatant. After washing, the pellet was resuspended by adding $5 \mathrm{~mL}$ of DI water. $10 \mu \mathrm{L}$ of copper particle solution was extracted and placed onto a flat SEM post. The posts were placed in a vacuum oven to prevent oxidation and to evaporate the residual water.

\subsection{Imaging}

Copper particles were imaged using scanning electron microscopy. Samples were placed in a Phillips FEI XL30 with an FEI Sirion column that allows for resolutions up to $1 \mathrm{~nm}$ at $10 \mathrm{kV}$. An Oxford energy dispersive X-ray spectroscopy (EDX) instrument was used to perform elemental analysis to confirm the presence of copper in the SEM images.

\section{Results and Discussion}

High quality copper particles resulting from the reduction of Schweizer's reagent formed were desired. To that end, three parameters were optimized: the $\mathrm{NH}_{3} / \mathrm{Cu}^{2+}$ molar ratio in the precursor solution, the $\mathrm{pH}$ by adjusting the amount of ascorbic acid added to the reaction mixture, and the amount of gum arabic introduced into reaction solution.

\subsection{Optimization of the Precursor Solution}

$12.5 \mathrm{~g}$ of copper sulfate and different amounts of concentrated ammonium hydroxide mixed together and dissolved in DI water to achieve $500 \mathrm{~mL}$ stock solutions with $\mathrm{NH}_{3} / \mathrm{Cu}^{2+}$ ratios of $0,1.15,2.30,4.60,6.90$, and 9.20. $10 \mathrm{~mL}$ aliquots of these stock solutions were transferred to $20 \mathrm{~mL}$ glass vials and reduced with $10 \mathrm{~mL}$ of $0.3 \mathrm{M}$ ascorbic acid. The reaction mixture was allowed to deposit on the sides of the glass vials for 24 hours at $15^{\circ} \mathrm{C}-20^{\circ} \mathrm{C}$. Visual inspection of the film color, smoothness and reflectivity was used to determine the best reaction conditions for the set. A copper sulfate solution with a $\mathrm{NH}_{3} / \mathrm{Cu}^{2+}$ ratio of 6.90 provided the most consistent and highest quality plating on the vial walls.

Using the 6.90 ratio as a starting point, the precursor solution was finely tuned with stepwise additions of 50 $\mu \mathrm{L}$ of concentrated ammonium hydroxide to a $10 \mathrm{~mL}$ 6.90 ratio sample. These stepwise additions were made every 2 hours until another addition of ammonium hydroxide caused the solution to turn clear. This fine adjustment resulted in an optimal precursor solution with $\mathrm{NH}_{3} / \mathrm{Cu}^{2+}$ ratio of 7.13.

\subsection{Optimization of $\mathbf{p H}$}

After the precursor solution was optimized the best reaction mixture needed to be determined. Starting with 10 $\mathrm{mL}$ of 7.12 ratio precursor, reaction solutions were prepared with $0.3 \mathrm{M}$ ascorbic acid added in volumes between 0 to $10 \mathrm{~mL}$ in $0.5 \mathrm{~mL}$ steps and the remainder 
filled with DI water to a total reaction volume of $20 \mathrm{~mL}$ (Figure 1). Visual inspection for film color, smoothness, and reflectivity was once again used to determine film quality. Determining the optimal $\mathrm{pH}$ of the solution was based on the color of the solution. If the solution was too green, the mixture was too acidic; if the solution were too basic the solution would turn yellow. The amount of ascorbic acid was adjusted carefully to turn the solution clear and then follow through to green (Figure 1(b)). This corresponded to a molar ratio of ascorbic acid to copper of 2.55 at a $\mathrm{pH}$ of 8.5 .

\subsection{Optimization of Gum Arabic Concentration}

A series of reaction solutions were prepared with the $1 / 7.13 / 2.55$ solution and final concentration of gum arabic between $0 \%-2.26 \% \mathrm{w} / \mathrm{v}$ as listed in Table 1. Upon SEM imaging, it was determined that a final concentration in solution above approximately $0.16 \% \mathrm{w} / \mathrm{v}$ induced the formation of highly crystalline copper microparticles (Figure 2) Higher concentrations produced relatively regular single crystals ranging between 0.5 to $2 \mu \mathrm{m}$. These solutions reacted under vigorous stirring and elevated temperatures $\left(100^{\circ} \mathrm{C}\right)$.

It was found upon examination of the SEM images that the gum arabic acted both as binding and capping agent depending on the concentration. At low concentrations, small droplets of gum arabic served as nucleation centers by binding many small copper seeds and allowlowing an orderly crystallization around it (Figure 3(a)). However, at higher concentrations, the gum arabic drop

(a)

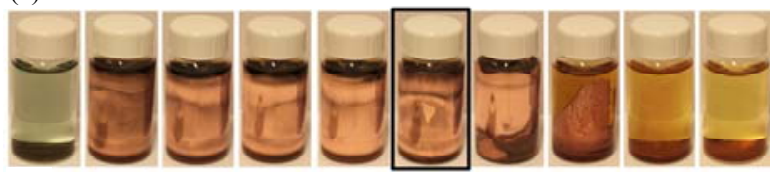

(b)

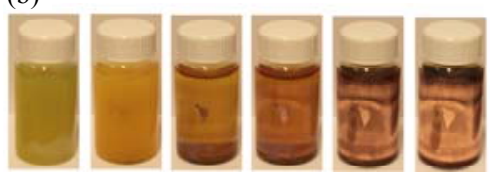

Figure 1. Plating quality with varying ascorbic acid content/ pH (a) Finding the right plating in the copper after $168 \mathrm{hrs}$. Start on the left increasing amounts of $0.5 \mathrm{~mL}$ L-ascorbic acid was added to $10 \mathrm{~mL}$ of an Ammonium hydroxide/ Copper sulfate solution mixed to a mole ratio of $\mathrm{NH}_{4} / \mathrm{Cu}=$ 7.12. From left to right: $1,2.5,4,5.5,7$ (pH 8.9), 8.5 (pH 8.5), 10 (pH 7.5), 11.5, 13, $15 \mathrm{~mL}$ of $\mathrm{L}$-ascorbic acid were added to solution and deionized water was used to raise the volume to $20 \mathrm{~mL}$. On visual inspection, the best the condition was found to be $8.5 \mathrm{~mL}$ of L-ascorbic acid with a pH 8.5. The best sample is indicated by a black box around the sample. (b) Time elapsed observation of the optimal condition $(8.5 \mathrm{~mL}$ of ascorbic acid) (left to right) $5 \mathrm{~min} ., 1 \mathrm{hr}, 4.5$ hr, 7.5 hr, 28 hr, 168 hr. lets became incorporated into the copper crystal facets, spreading out, and limiting further incorporation of copper into the particle (Figure 3(b)). Energy-dispersive X-ray (EDX) spectroscopy was used confirm that particles observed were composed of copper (Figure 4).

On the other hand, while ascorbic acid reduction of Schwiezer's reagent is specific to copper sulfate-ammonium solutions, we explored the use of other copper salts like copper hydroxide and copper nitrate. Preliminary work in this area allowed the formation of copper films on reaction vials using various $\mathrm{NH}_{3} / \mathrm{Cu}$ ratios.

\section{Conclusion}

Schweizer's reagent was optimized and reduced with ascorbic acid in the presence of gum arabic to produce
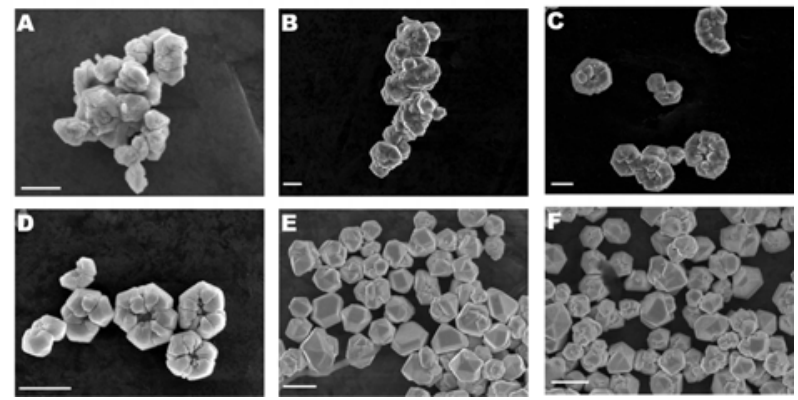

Figure 2. Transition from grainy to highly crystalline objects. SEM shows the particle formation with increasing gum arabic concentration (w/v) (A) $0 \%$ (B) $0.014 \%$ (C) $0.12 \%$, (D) $0.16 \%$, (E) $0.32 \%$, (F) $0.34 \%$. All scale bars are 1 micron. (a)
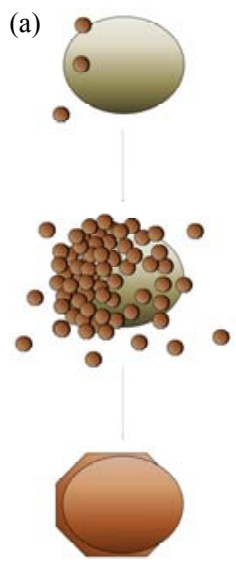

(b)

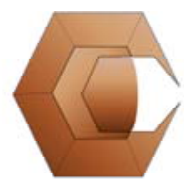

(c)

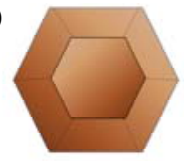

(d)

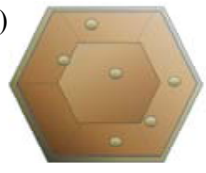

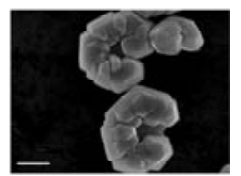
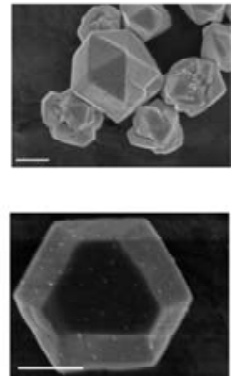

Figure 3. Proposed model for the role of gum arabic. Scale bars are $500 \mathrm{~nm}$. (a) Gum arabic acts as a binding agent pulling in copper seeds and growing larger. (b) Below the threshold, not enough gum arabic is around to form nice complete copper microparticles. (c) At the threshold value nice copper particles formed. d) Much above the threshold, the gum arabic starts to act as a capping agent, embedding itself in the copper crystal and limiting further inclusion of copper from solution in the crystal. 

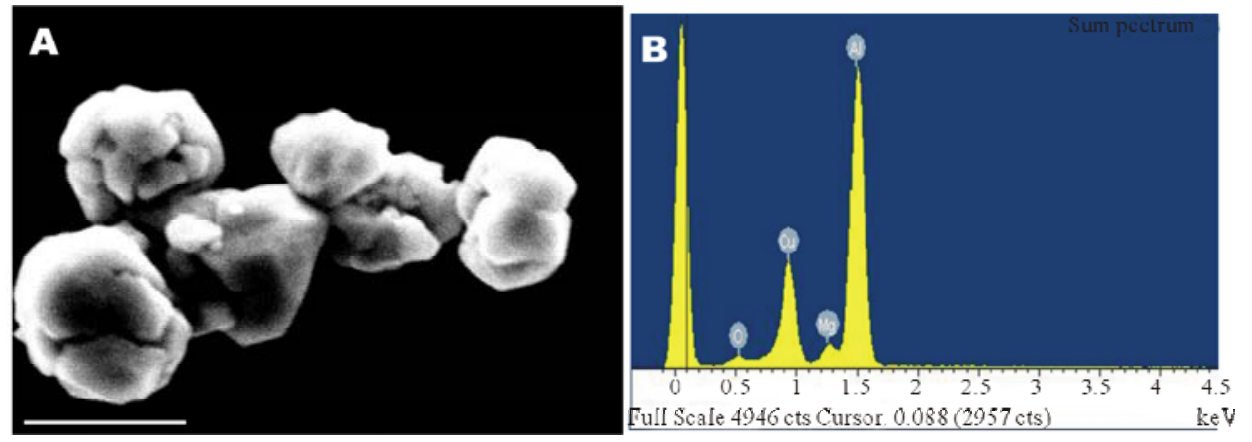

Figure 4. EDX confirmation that particles are copper. Scale bars are $1 \mu \mathrm{m}$. (A) SEM image of the particle under analysis. (B) Sample EDX analysis of shows presence of copper in the particles. Other elemental peaks are ascribed to the aluminum alloy SEM holder.

Table 1. Concentration of reaction mixtures tested at $\mathrm{pH} 8.5$ at $100^{\circ} \mathrm{C}$.

\begin{tabular}{|c|c|c|c|c|c|}
\hline$\left[\mathrm{Cu}^{2+}\right](\mathrm{M})$ & [Ammonium] (M) & [Ascorbic Acid] (M) & [Gum arabic] (\% w/v) & [Ammonium]/[Copper] & {$[$ Ascorbic Acid] $/[\mathrm{Cu}]$} \\
\hline 0.054 & 0.384 & 0.137 & $0.014 \%$ & 7.13 & 2.55 \\
\hline 0.054 & 0.382 & 0.137 & $0.04 \%$ & 7.13 & 2.55 \\
\hline 0.053 & 0.376 & 0.135 & $0.12 \%$ & 7.13 & 2.55 \\
\hline 0.025 & 0.178 & 0.064 & $0.16 \%$ & 7.13 & 2.55 \\
\hline 0.025 & 0.178 & 0.064 & $0.32 \%$ & 7.13 & 2.55 \\
\hline 0.050 & 0.359 & 0.128 & $0.34 \%$ & 7.13 & 2.55 \\
\hline 0.049 & 0.347 & 0.124 & $0.50 \%$ & 7.13 & 2.55 \\
\hline 0.025 & 0.178 & 0.064 & $0.54 \%$ & 7.13 & 2.55 \\
\hline 0.047 & 0.336 & 0.120 & $0.64 \%$ & 7.13 & 2.55 \\
\hline 0.046 & 0.326 & 0.117 & $0.77 \%$ & 7.13 & 2.55 \\
\hline 0.049 & 0.347 & 0.124 & $0.99 \%$ & 7.13 & 2.55 \\
\hline 0.025 & 0.178 & 0.064 & $1.08 \%$ & 7.13 & 2.55 \\
\hline 0.048 & 0.342 & 0.122 & $1.13 \%$ & 7.13 & 2.55 \\
\hline 0.047 & 0.336 & 0.120 & $1.27 \%$ & 7.13 & 2.55 \\
\hline 0.046 & 0.326 & 0.117 & $1.54 \%$ & 7.13 & 2.55 \\
\hline 0.025 & 0.178 & 0.064 & $1.61 \%$ & 7.13 & 2.55 \\
\hline 0.044 & 0.316 & 0.113 & $1.80 \%$ & 7.13 & 2.55 \\
\hline 0.042 & 0.298 & 0.107 & $2.26 \%$ & 7.13 & 2.55 \\
\hline
\end{tabular}

highly crystalline copper particles between $0.5-2 \mu \mathrm{m}$. The gum arabic was observed to serve as binding agent in low concentrations and a capping agent in higher concentrations. Highly crystalline copper micro/nanoparticles were synthesized using environmentally friendly reagents requiring few steps.

\section{Acknowledgements}

This work was supported by UCSD Startup Funds and by the Welch Foundation Grant BG-0017.

\section{REFERENCES}

[1] N. A. Dhas, C. P. Raj and A. Gedanken, "Synthesis, Characterization, and Properties of Metallic Copper Nanoparticles," Chemistry of Materials, Vol. 10, No. 5, 1998, pp. 1446-1452. http://dx.doi.org/10.1021/cm9708269

[2] H. Ching-Yen, T. Yu-Hsiang and S. Feng-Ming, "Thermal Transport in the Copper Powders with Nanometer and Micrometer Particles," Advanced Materials Research, Vol. 126-128, 2010, pp. 952-956956.

http://dx.doi.org/10.4028/www.scientific.net/AMR.126-1 $\underline{28.952}$ 
[3] K. P. Rice, E. J. Walker, M. P. Stoykovich and A. E. Saunders, "Solvent-Dependent Surface Plasmon Response and Oxidation of Copper Nanocrystals," Journal of Physical Chemistry C, Vol. 115, No. 5, 2011, pp. 17931799. http://dx.doi.org/10.1021/jp110483z

[4] T. Tsing-Tshih, C. Ho, C. Liang-Chia, H. Lee-Long, L. Chih-Hung and L. Ming-Kun, "Development of Pressure Control Technique of an Arc-Submerged Nanoparticle Synthesis System (ASNSS) for Copper Nanoparticle Fabrication" Materials Transactions, Vol. 44, No. 6, 2003, pp. 1138-1142.

http://dx.doi.org/10.2320/matertrans.44.1138

[5] S. Noël, J. Hermann and T. Itina, "Investigation of Nanoparticle Generation during Femtosecond Laser Ablation of Metals," Applied Surface Science, Vol. 253, No. 15, 2007, pp. 6310-6315.

http://dx.doi.org/10.1016/j.apsusc.2007.01.081

[6] M. Biçer and I. Şişman, "Controlled Synthesis of Copper Nano/Microstructures Using Ascorbic Acid in Aqueous CTAB Solution," Powder Technology, Vol. 198, No. 2, 2010, pp. 279-284284. http://dx.doi.org/10.1016/j.powtec.2009.11.022

[7] M. Blosi, S. Albonetti, M. Dondi, C. Martelli and G. Baldi, "Microwave-Assisted Polyol Synthesis of $\mathrm{Cu} \mathrm{Na}-$ noparticles," Journal of Nanoparticle Research, Vol. 13, No. 1, 2011, pp. 127-138. http://dx.doi.org/10.1007/s11051-010-0010-7

[8] D. Ensign, M. Young and T. Douglas, "Photocatalytic Synthesis of Copper Colloids from $\mathrm{Cu}$ (II) by the Ferrihydrite Core of Ferritin," Inorganic Chemistry, Vol. 43, No. 11, 2004, pp. 3441-3446. http://dx.doi.org/10.1021/ic035415a

[9] D. Mott, J. Galkowski, L. Wang, J. Luo and C.-J. Zhong, "Synthesis of Size-Controlled and Shaped Copper Nanoparticles," Langmuir, Vol. 23, No. 10, 2007, pp. 57405745. http://dx.doi.org/10.1021/la0635092

[10] A. G. Nasibulin, P. P. Ahonen, O. Richard, E. I. Kauppinen and I. S. Altman, "Copper and Copper Oxide Nanoparticle Formation by Chemical Vapor Nucleation from Copper (II) Acetylacetonate," Journal of Nanoparti- cle Research, Vol. 3, No. 5-6, 2001, pp. 385-400.
[11] W. Songping, "Preparation of Fine Copper Powder Using Ascorbic Acid as Reducing Agent and Its Application in MLCC," Materials Letters, Vol. 61, No. 4-5, 2007, pp. 1125-1129. http://dx.doi.org/10.1016/j.matlet.2006.06.068

[12] S.-H. Wu and D.-H. Chen, "Synthesis of High-Concentration $\mathrm{Cu}$ Nanoparticles in Aqueous CTAB Solutions," Journal of Colloid and Interface Science, Vol. 273, No. 1, 2004, pp. 165-169. http://dx.doi.org/10.1016/j.jcis.2004.01.071

[13] J. G. Brandon C. Jarvis, G. Ussery, J. K. Schaefers, T. E. Renfro, R. Glosser and P. B. Landon, "Synthesis and Optical Properties of Micron Sized Metallic Colloidal Copper and Self Assembled Opals Composed of Micron Sized Metallic Silver Spheres," SPIE Conference-Optical Materials and Structures Technologies, San Diego, July 2005.

[14] P. B. Landon, "Nano-Engineering of Colloidal Particles, Synthetic Biomimetic Blood Cells, Synthetic Opals, Photonic Crystals and the Physics of Self-Assembling Nanostructures," PhD Thesis, University of Texas, Dallas, UMI Publishers, 2005.

[15] C. C. Wu and D. H. Chen, "Facile Green Synthesis of Gold Nanoparticles with Gum Arabic as a Stabilizing Agent and Reducing Agent," Gold Bulletin, Vol. 43, No. 4, 2010, pp. 234-240. http://dx.doi.org/10.1007/BF03214993

[16] K. P. Velikov, G. E. Zegers and A. van Blaaderen, "Synthesis and Characterization of Large Colloidal Silver Particles," Langmuir, Vol. 19, No. 4, 2003, pp. 1384-1389. http://dx.doi.org/10.1021/la026610p

[17] I. L. Batalha, A. Hussain and A. C. A. Roque, "Gum Arabic Coated Magnetic Nanoparticles with Affinity Ligands Specific for Antibodies," Journal of Molecular Recognition, Vol. 23, No. 5, 2010, pp. 462-471. http://dx.doi.org/10.1002/jmr.1013 